\title{
Regioselectivity of aryl azide cycloaddition to methyl propiolate in aqueous media: experimental evidence versus local DFT HSAB principle
}

\author{
Giorgio Molteni ${ }^{a, *}$ and Alessandro Ponti ${ }^{b}$ \\ ${ }^{a}$ Università degli Studi di Milano, Dipartimento di Chimica Organica e Industriale, via Golgi \\ 19, 20133 Milano, Italy \\ ${ }^{b}$ Consiglio Nazionale delle Ricerche, Istituto di Scienze e Tecnologie Molecolari, via Golgi 19, \\ 20133 Milano, Italy \\ E-mail: giorgio.molteni@unimi.it
}

\begin{abstract}
The regioselectivity of the 1,3-dipolar cycloaddition of a series of 4-substituted-phenyl azides to methyl propiolate in aqueous medium has been determined experimentally. Ab initio B3LYP/6$311+\mathrm{G}(\mathrm{d}, \mathrm{p})$ calculations in conjunction with the local HSAB principle developed within density functional theory provided a full rationalization of cycloaddition regioselectivity.
\end{abstract}

Keywords: 1,3-Dipolar cycloaddition, azides, hard-soft acid-base principle, density functional theory

\section{Introduction}

1,2,3-Triazoles ${ }^{1}$ display a wide range of biological activity as anti-HIV ${ }^{2}$ and anti-microbial ${ }^{3}$ agents as well as selective $\beta_{3}$ adrenergic receptor agonist. ${ }^{4}$ The azide-acetylene cycloaddition, which constitutes the choice route to 1,2,3-triazoles, ${ }^{5}$ typically yields a mixture of 4- and 5regioisomers. After the pioneering work of Huisgen, ${ }^{6}$ a number of reaction conditions have been exploited in the field of the azide-alkyne cycloaddition in order to broaden the scope of such a transformation. As far as regioselectivity is concerned, high selectivity towards 4-regioisomer has been recently achieved when $\mathrm{Cu}(\mathrm{I})$ is present, ${ }^{7}$ while mixtures of regioisomeric 1,2,3triazoles were obtained in hot water as reaction medium. ${ }^{8}$ In this latter report by Wang and Qin it was noted that the behaviour of various aryl azides toward methyl propiolate did not harmonize with the FMO expectations.

The aim of this paper is to demonstrate that regioselectivities of the above cycloaddition can be predicted quantitatively with high accuracy by means of a generalization of the local HSAB principle $^{10}$ developed within the framework of the density functional theory (DFT). ${ }^{11}$ Such an 
approach has provided many reliable qualitative $^{12}$ and quantitative $^{13}$ predictions of $^{2}$ regioselectivity for 1,3-dipolar cycloadditions.

Furthermore, the choice of the aqueous medium reflects the fact that water as a solvent displays a number of desirable features: (i) reaction rates can be significantly increased, (ii) product isolation can be achieved by simple filtration and (iii) environmentally-friendly procedures can be successfully elaborated.

\section{Results and Discussion}

The 1,3-dipolar species 2 were prepared from the corresponding anilines as depicted in Scheme 1 and then reacted with methyl propiolate by heating aqueous mixtures of the reactants at $90^{\circ} \mathrm{C}$ in the presence of tetrahexylammonium chloride (THAC) as a catalyst. The main experimental results are collected in Table 1.

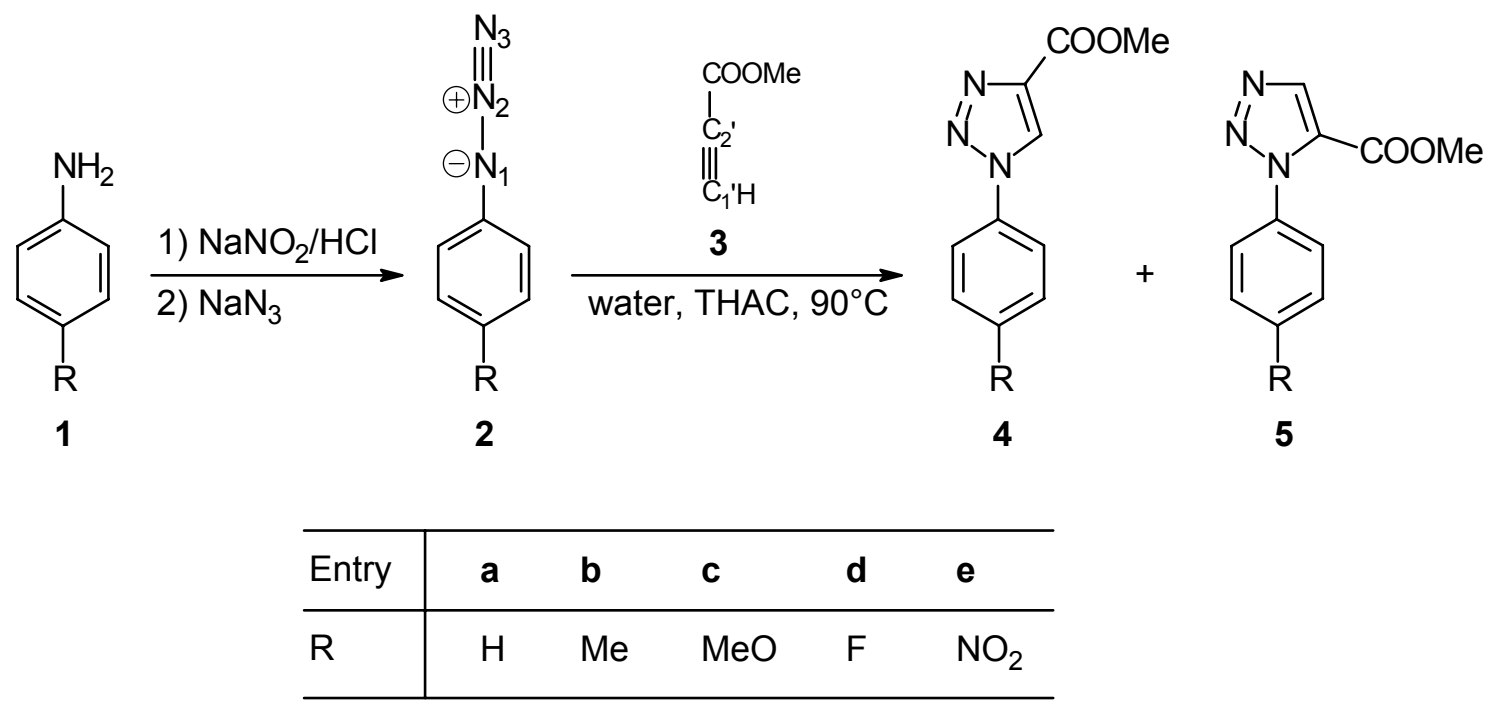

\section{Scheme 1}

Very short reaction times were experienced in the presence of THAC in comparison to the non-catalyzed cycloaddition conditions. ${ }^{8}$ The structures of the regioisomeric 1-(4-substituted)phenyl-4-methoxycarbonyl-1,2,3-triazoles 4 and 1-(4-substituted)phenyl-5-methoxycarbonyl1,2,3-triazoles 5 were proved by comparison with authentic samples, while their regioisomeric ratios were deduced from ${ }^{1} \mathrm{H}-\mathrm{NMR}$ spectra of crude reaction mixtures. As can be inferred from Table 1, the regioselectivity outcome can hardly be rationalized by consideration of the substituent electron-demand features. Indeed, the lowest regioselectivity is observed with the most electron-donating $(\mathrm{MeO})$ and -accepting $\left(\mathrm{NO}_{2}\right)$ substituents. Linear regression of the yield ratios versus Hammett $\sigma \rho$ values results in scattered plots with low correlation coefficient $\rho<$ 
0.7. As far as FMO theory is concerned, at its best it allows a qualitative prediction of the regioselectivity involved in the cycloadditions between aryl azides and methyl propiolate. This latter phenomenon is based upon the effectiveness of both HOMO-LUMO interactions in which the predominance of HOMO-dipole control leads to the major cycloadduct 4 . However, the substituent effect remains unexplained since the difference between the $\operatorname{LUMO}(2) / \operatorname{HOMO}(3)$ and the $\operatorname{LUMO}(3) / \mathrm{HOMO}(2)$ interaction energies (Table 2) increases with the electron-donating strength of the ring substituent whereas the regioselectivity is minimal at both ends of the electron-demand scale.

Table 1. Experimental yields and regioisomeric ratios of the cycloaddition between aryl azides $\mathbf{2}$ and methyl propiolate

\begin{tabular}{llccc}
\hline Entry & $\mathrm{R}$ & Time $(\min )$ & Yield $\mathbf{4}+\mathbf{5}(\%)$ & Yield Ratio $\mathbf{4}: \mathbf{5}$ \\
\hline a & $\mathrm{H}$ & 60 & 92 & $82: 18$ \\
$\mathbf{b}$ & $\mathrm{Me}$ & 40 & $>95$ & $75: 25$ \\
c & $\mathrm{MeO}$ & 30 & 92 & $78: 22$ \\
d & $\mathrm{F}$ & 120 & 94 & $82: 18$ \\
e & $\mathrm{NO}_{2}$ & 300 & $>95$ & $60: 40$ \\
\hline
\end{tabular}

${ }^{\mathrm{a}}$ Isolation yields. ${ }^{\mathrm{b}}$ Deduced from ${ }^{1} \mathrm{H}$ NMR of reaction crudes.

Table 2. B3LYP/6-311+G(d,p) FMO energies and energy differences (eV) of aryl azides 2 and methyl propiolate $\mathbf{3}$. The aqueous solvent is treated as pure water by the COSMO continuum model

\begin{tabular}{lccc}
\hline Entry & HOMO & LUMO & $\begin{array}{c}{[\mathrm{LUMO}(\mathbf{2})-\mathrm{HOMO}(\mathbf{2})]^{-}} \\
{[\mathrm{LUMO}(\mathbf{3})-\mathrm{HOMO}(\mathbf{3})]^{\mathrm{a}}}\end{array}$ \\
\hline $\mathbf{2 a}$ & -6.52 & -1.45 & -2.26 \\
$\mathbf{2 b}$ & -6.33 & -1.42 & -2.48 \\
$\mathbf{2 c}$ & -6.05 & -1.42 & -2.77 \\
$\mathbf{2 d}$ & -6.49 & -1.47 & -2.27 \\
$\mathbf{2 e}$ & -6.52 & -1.52 & -2.19 \\
$\mathbf{3}$ & -8.36 & -1.87 & - \\
\hline
\end{tabular}

${ }^{a}$ This is the difference between the $\operatorname{LUMO}(2) / \operatorname{HOMO}(3)$ and the $\operatorname{LUMO}(3) / \operatorname{HOMO}(2)$ interaction energies.

Since our work is aimed to a deeper, quantitative understanding of the regioselectivity of the cycloaddition between $\mathbf{2}$ and $\mathbf{3}$, we turned our attention to the local HSAB principle, as formulated within DFT.

The main results of DFT calculations at the B3LYP/6-311+G(d,p) level including solvent effects are reported in Table 3. 
Table 3. Results of $B 3 \mathrm{LYP} / 6-311+\mathrm{G}(\mathrm{d}, \mathrm{p})$ calculations including solvent effect. ${ }^{\mathrm{a}}$ Electron chemical potential difference between aryl azides $\mathbf{2}$ and methyl propiolate 3 along with the $\delta \Delta \Omega$ difference $^{\mathrm{b}}$ and predicted $\mathbf{4}: \mathbf{5}$ yield ratio for their mutual cycloaddition

\begin{tabular}{lccc}
\hline $\mathrm{R}$ & $\begin{array}{c}\mu(2)-\mu(3) \\
(\mathrm{eV})\end{array}$ & $\begin{array}{c}\delta \Delta \Omega \\
\left(\mathrm{kJ} \mathrm{mol}^{-1}\right)\end{array}$ & Predicted ratio $^{\mathrm{c}} \mathbf{4}: \mathbf{5}$ \\
\hline $\mathrm{H}$ & 1.20 & -1.68 & $83: 17$ \\
$\mathrm{Me}$ & 1.30 & -0.93 & $74: 26$ \\
$\mathrm{MeO}$ & 1.45 & -1.23 & $78: 22$ \\
$\mathrm{~F}$ & 1.19 & -1.57 & $82: 18$ \\
$\mathrm{NO}_{2}$ & 0.16 & -0.03 & $60: 40$ \\
\hline
\end{tabular}

${ }^{a}$ Water is modeled as a continuum by the COSMO model. ${ }^{\mathrm{b}}$ Difference in grand potential variation for the pathways leading to triazoles 4 and $5 .{ }^{c}$ From computed $\delta \Delta \Omega$ and equations (2) and (3). Estimated error $\pm 1 \%$

In aqueous solution, the chemical potential of 2a-e is larger than that of $\mathbf{3}$, i.e., upon reactive encounter, charge flows from any aryl azide to methyl propiolate. The stabilization of the promoted complex for the pathway leading to 4-methoxy carbonyl-1,2,3-triazole 4 is ${ }^{11}$

$\Delta \Omega(4)=-(1 / 2)[\mu(\mathbf{2})-\mu(\mathbf{3})]^{2}\left\{s\left(\mathrm{~N}_{1}\right) s\left(\mathrm{C}_{1}\right)\left[s\left(\mathrm{~N}_{1}\right)+s\left(\mathrm{C}_{1}\right)\right]^{-1}+s\left(\mathrm{~N}_{3}\right) s\left(\mathrm{C}_{2}\right)\left[s\left(\mathrm{~N}_{3}\right)+s\left(\mathrm{C}_{2}\right)\right]^{-1}\right\}$

where the atoms are numbered as in Scheme 1. $\Delta \Omega(5)$ can be obtained by exchanging $s(\mathrm{C} 1)$ and $s(\mathrm{C} 2)$. The difference $\delta \Delta \Omega=\Delta \Omega(\mathbf{4})-\Delta \Omega(\mathbf{5})$ is reported in Table 3. The negative sign of $\delta \Delta \Omega$ shows that the cycloadduct 4 is always the major one, in line with the experimental results. We now proceed one step further by quantitatively comparing $\delta \Delta \Omega$ with the difference in activation energy $\delta \Delta \mathrm{E}^{\ddagger}$ of the two reaction paths that is obtained as $\delta \Delta \mathrm{E}^{\ddagger}=-R T \log (Y)$, where $T$ is the reaction temperature, and $Y$ is the experimental ratio of $4: 5( \pm 1 \%)$. Results for the cycloaddition carried out in aqueous medium yield a significant linear regression; the result is:

$\delta \Delta \Omega=(0.49 \pm 0.03) \delta \Delta E^{\ddagger}+(0.57 \pm 0.07) \mathrm{kJ} \mathrm{mol}^{-1}, \quad \rho=0.997$

where $\rho$ is the linear correlation coefficient (see Figure 1). The rather small regression slope means that the aqueous medium makes the energy differences within the promoted complexes proportionally smaller than in the transition states. The low regioselectivity of $2 \mathbf{e}$ is due to the small difference of electron chemical potential to $\mathbf{3}$, a global electronic effect which smoothes differences among atom-atom interactions. In the other cases, however, local interactions are essential for the regioselectivity as can be appreciated by noting that the most electron-donating substituent $\mathrm{R}=\mathrm{OMe}$ in $\mathbf{2 c}$ falls between $\mathrm{R}=\mathrm{NO}_{2}, \mathbf{2 e}$, and $\mathrm{R}=\mathrm{H}$, 2a.

The highly polar aqueous medium has a larger effect on the electronic structure of the reactants. The results suggest that the reaction path is influenced so that the energy difference 
between the promoted complexes is not equal to, but rather is proportionally smaller than, the differences in activation energy. However, specific solvent-solute interactions seem not to be present.

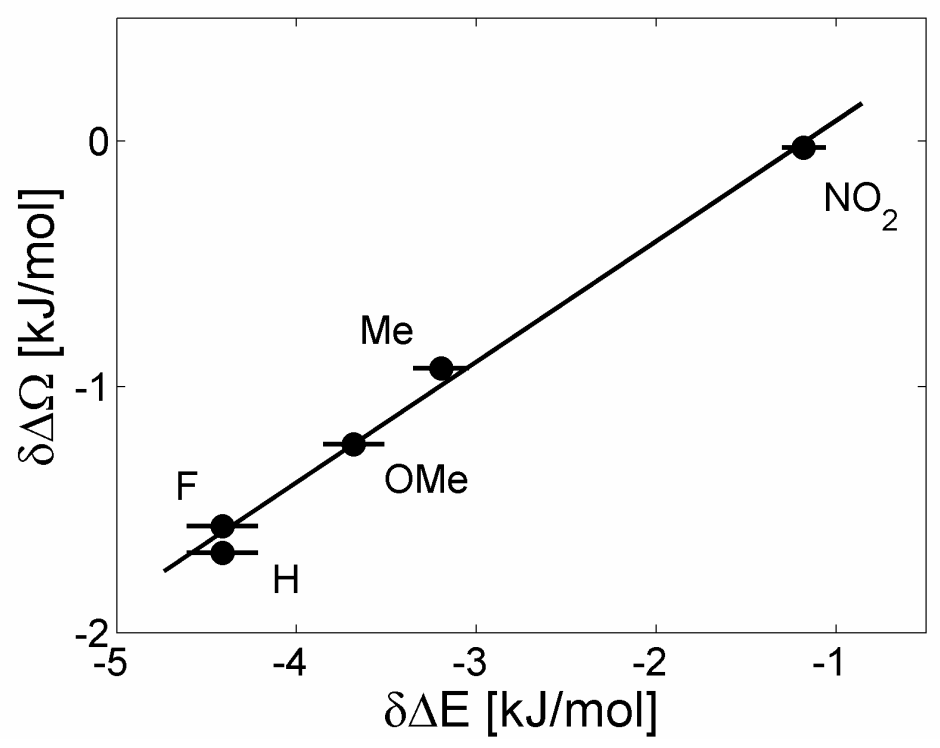

Figure 1. Linear relationship between the computed difference $\delta \Delta \Omega$ of the promoted-complex stabilization for the pathways leading to cycloadducts $\mathbf{4}$ and $\mathbf{5}$ and the correspondent difference in activation energy $\delta \Delta E^{\ddagger}$, obtained from the experimental $4: 5$ yield ratio in aqueous media. Bars denote the estimated uncertainty on the experimental activation energy.

In conclusion, we have developed a new and effective protocol allowing fast and clean cycloaddition between aryl azides and methyl propiolate, which occurs in aqueous media in the presence of a phase transfer catalyst. As a major task, the observed regioselectivities have been fully explained in the light of the HSAB principle developed within the framework of density functional theory.

\section{Computational methods}

DFT calculations were performed with the Gaussian $98^{14}$ program suite. The B3LYP functional was employed with the standard $6-311+\mathrm{G}(\mathrm{d}, \mathrm{p})$ basis set. The geometry of $2 \mathrm{a}-\mathrm{e}$ and 3 was fully optimised in vacuo and characterized with vibrational analysis at the same level of theory. The effect of the aqueous solvent was taken into account by performing calculations of 2a-e and 3 by the COSMO mode ${ }^{15}$ with the parameters for pure water at the in-vacuo geometry.

The anion and cation of all systems were treated at the UB3LYP/6-311+G(d,p) level using the geometry of the neutral systems. Atomic electron populations were evaluated following the Merz-Kollman scheme ${ }^{16,17}$ (including fitting of atom-centred dipoles). Reactivity indices were computed within the finite difference approximation: $\mu=-($ IP+EA $) / 2$ and $S=(\text { IP-EA })^{-1}$, where 
IP and EA are the (vertical) ionisation potential and electron affinity, obtained as energy difference of the neutral with the cation and anion, respectively. The local softness $s$ (condensed to each individual atom ${ }^{18}$ ) was computed as $s^{+}=S\left[p\left(N_{0}+1\right)-p\left(N_{0}\right)\right]$ for electrophiles, and as $s^{-}=$ $S\left[p\left(N_{0}\right)-p\left(N_{0}-1\right)\right]$ for nucleophiles, where $p(N), N=N_{0}-1, N_{0}, N_{0}+1$, is the atomic electron population of the cationic, neutral, and anionic system, respectively.

The atoms in a molecule are open subsystems exchanging energy and electrons, so the natural thermodynamic quantity is the grand potential $\Omega=E-N \mu$, where $E$ is the energy. Consider the cycloaddition of molecules $A$ and $B$ to give $A B$. The interaction of atom $i$ of $A$ with atom $k$ of $B$ is

$$
\Delta \Omega_{i}^{k}=-\frac{1}{2}\left(\mu_{A}-\mu_{B}\right)^{2} \frac{s_{A i} s_{B k}}{s_{A i}+s_{B k}}
$$

and represents the stabilization due to the charge transfer between $A i$ and $B k$. Since cycloadditions are concerted reaction, the stabilization upon reactive encounter is due to two bond-forming interactions $A i \leftrightarrow B k$ and $A j \leftrightarrow B l$ and is written as $\Delta \Omega_{i j}^{k l}=\Delta \Omega_{i}^{k}+\Delta \Omega_{j}^{l}$. For the opposite regioisomer, the stabilization is $\Delta \Omega_{i j}^{l k}=\Delta \Omega_{i}^{l}+\Delta \Omega_{j}^{k}$. The stabilization difference $\delta \Delta \Omega=\Delta \Omega_{i j}^{k l}-\Delta \Omega_{i j}^{l k}$ is the computed quantity that parallels the activation energy difference $\delta \Delta E^{\ddagger}$ in the regioisomeric transition states obtained from the experimental regioselectivity.

\section{Experimental Section}

Compounds 4a-e, and 5a-e are known in the literature. ${ }^{19}$

Synthesis of the 1-(4-substituted)phenyl-4-methoxycarbonyl-1,2,3-triazoles, 4, and 1-(4substituted)-phenyl-5-methoxycarbonyl-1,2,3-triazoles, 5, in water. General procedure. A mixture of the appropriate aryl azide $2(5.0 \mathrm{mmol})$, methyl propiolate $(0.67 \mathrm{~g}, 8.0 \mathrm{mmol})$, THAC $(0.19 \mathrm{~g}, 0.5 \mathrm{mmol})$ and water $(20 \mathrm{~mL})$ was vigorously stirred at $90{ }^{\circ} \mathrm{C}$ for the time indicated in Table 1. Filtration gave a residue, which was chromatographed on a silica gel column with ethyl acetate-hexane, 2:1. The major regioisomer 4 was eluted first, followed by the minor isomer, 5.

\section{Acknowledgements}

Thanks are due to MIUR and CNR for financial support. 


\section{References}

1. Lwowsky, W. In 1,3-Dipolar Cycloaddition Chemistry; Padwa, A. Ed.; Wiley-Interscience: New York, 1984; Vol. 1, Chapter 4, pp 621-627.

2. Velazquez, S.; Alvarez, R.; Perez, C.; Gago, F.; De, C.; Balzarini, J.; Camarasa, M. J. Antivir. Chem. Chemother. 1998, 9, 481. (b) Alvarez, R.; Velazquez, S.; San, F.; Aquaro, S.; De, C.; Perno, C.; Karlsson, A.; Balzarini, J.; Camarasa, M. J. J. Med. Chem. 1994, 37, 4185.

3. Genin, M. J.; Allwine, D. A.; Anderson, D. J.; Barbachyn, R.; Emmert, D. E.; Garmon, D. A.; Graber, D. R.; Grega, K. C.; Hester, J. B.; Hutchinson, D. K.; Morris, J.; Reischer, R. J.; Ford, C. W.; Zurenko, G. E.; Hamel, J. C.; Schaadt, R. D.; Stapert, J. B. J. Med. Chem. 2000, 43, 953.

4. Brockunier, L. L.; Parmee, E. R.; Ok, O. H.; Candelore, M. R.; Cascieri, M. A.; Colwell, L. F.; Deng, L.; Feeney, W. P.; Forrest, M. J.; Hom, G.; MacIntyre, J. D. E.; Tota, L.; Wywratt, M. J.; Fisher, M. H.; Weber, A. E. Bioorg. Med. Chem. Lett. 2000, 10, 2111.

5. Scriven, E. F. V.; Turnbull, K. Chem. Rev. 1988, 88, 297.

6. Huisgen, R.; Grashey, R.; Seifidel, M.; Wallbillich, G.; Knupfer, H.; Schmidt, R. Ann. Chem. 1962, 653, 105.

7. Tornøe, C. W.; Christensen, C.; Meldal, M. J. Org. Chem. 2002, 67, 3057. (b) Rostovtsev, V. V.; Green, L. G.; Fokin, V. V.; Sharpless, K. B. Angew. Chem. Int. Ed. 2002, 41, 2596.

8. Wang, Z.-X.; Qin, H.-L. Chem. Commun. 2004, 2450.

9. Ponti, A. J. Phys. Chem. A 2000, 104, 8843.

10. Chattaraj, P. K.; Lee, H.; Parr, R. G. J. Am. Chem. Soc. 1991, 113, 1855. (b) Gázquez, J. L.; Méndez, F. J. Phys. Chem. 1994, 98, 4591. (c) Cedillo, A.; Chattaraj, P. K.; Parr, R. G. Int. J. Quant. Chem. 2000, 77, 403.

11. Parr, R. G.; Yang, W. Density Functional Theory of Atoms and Molecules; Oxford University Press: Oxford, 1989.

12. Le, T. N.; Nguyen, L. T.; Chandra, A. K.; De Proft, F.; Geerlings, P.; Nguyen, M. T. J. Chem. Soc., Perkin Trans. 2 1999, 1249. (b) Chandra, K.; Uchimaru, T.; Nguyen, M. T. J. Chem. Soc., Perkin Trans. 2 1999, 2117.

13. Ponti, A.; Molteni, G. J. Org. Chem. 2001, 66, 5252. (b) Molteni, G.; Ponti, A.; Orlandi, M. New J. Chem. 2002, 26, 1340. (c) Ponti, A.; Molteni, G. New J. Chem. 2002, 26, 1346.

14. Frisch, M. J.; Trucks, G. W.; Schlegel, H. B.; Scuseria, G. E.; Robb, M. A.; Cheeseman, J. R.; Zakrzewski, V. G.; Montgomery, Jr., J. A.; Stratmann, R. E.; Burant, J. C.; Dapprich, S.; Millam, J. M.; Daniels, A. D.; Kudin, K. N.; Strain, M. C.; Farkas, O.; Tomasi, J.; Barone, V.; Cossi, M.; Cammi, R.; Mennucci, B.; Pomelli, C.; Adamo, C.; Clifford, S.; Ochterski, J.; Petersson, G. A.; Ayala, P. Y.; Cui, Q.; Morokuma, K.; Rega, N.; Salvador, P.; Dannenberg, J. J.; Malick, D. K.; Rabuck, A. D.; Raghavachari, K.; Foresman, J. B.; Cioslowski, J.; Ortiz, J. V.; Baboul, A. G.; Stefanov, B. B.; Liu, G.; Liashenko, A.; Piskorz, P.; Komaromi, I.; Gomperts, R.; Martin, R. L.; Fox, D. J.; Keith, 
T.; Al-Laham, M. A.; Peng, C. Y.; Nanayakkara, A.; Challacombe, M.; Gill, P. M. W.; Johnson, B.; Chen, W.; Wong, M. W.; Andres, J. L.; Gonzalez, C.; Head-Gordon, M.; Replogle, E. S.; Pople, J. A. Gaussian 98; Gaussian Inc.: Pittsburgh, 2002.

15. Barone, V.; Cossi, M. J. Phys. Chem. A 1998, 102, 1995.

16. Singh, U. C.; Kollman, P. A. J. Comput. Chem. 1984, 5, 129.

17. Besler, B. H.; Merz Jr., K. M.; Kollman, P. A. J. Comput. Chem. 1990, 11, 431.

18. Yang, W.; Mortier, W. J. J. Am. Chem. Soc. 1986, 108, 5708.

19. Molteni, G.; Ponti, A. Chem. Eur. J. 2003, 9, 2770. 